\title{
The Fish in Secondary Prevention of Heart Disease (FISH) Survey-Primary Care Physicians and $\omega 3$ Fatty Acid Prescribing Behaviors
}

Robert C. Oh, MD, MPH, Shirley A. A. Beresford, PhD, and William E. Lafferty, MD

Purpose: Consumption of fish oil has been shown to reduce mortality in patients with cardiovascular disease (CVD). This study aims to determine the frequency and associations of dietary fish prescribing by family physicians.

Methods: A 22-item survey mailed to randomly selected Washington State family physicians.

Results: Nearly all agreed that nutrition is important in CVD prevention (99\%) and felt that they have an essential role in giving dietary advice $(\mathbf{9 2 \%})$. The majority $(57 \%) \mathrm{knew}$ of fish oil's effectiveness in secondary prevention of CVD. However, only $17 \%$ of respondents were identified as high fish prescribers. Knowledge of fish oil's benefit in sudden death reduction was associated with higher fish prescribers in bivariate $(P=.005)$ and multivariate analysis $(O R=2.77 ; 95$ th $\mathrm{CI}: 1.32$ to 5.82$)$. High fish prescribers were more likely to report having sufficient time to discuss dietary therapies in bivariate $(P=$ $.018)$ and multivariate analysis $(O R=1.43 ; 95$ th $\mathrm{CI}: 1.03$ to 1.98$)$.

Conclusions: Despite knowledge of fish oil's benefit and favorable attitudes toward nutritional therapy, family physicians infrequently recommend fish oils for their CVD patients. Strategies improving awareness of fish oil's effects on sudden death and reducing time barriers associated with dietary counseling should be explored further to increase recommendation of this important advice. ( $\mathrm{J}$ Am Board Fam Med 2006;19:459-67.)

Cardiovascular disease (CVD) remains the number one killer of men and women in the United States. ${ }^{1}$ Although the role of dietary therapy has been integral for both primary and secondary prevention of CVD, the evidence for dietary modification and its reduction of all-cause mortality is limited. ${ }^{2}$ The National Cholesterol and Education Program's step I and step II diets (low saturated fats, whole grain, high fruits, and vegetable diet) targets cholesterol reduction to reduce CVD. ${ }^{3}$ Similarly, high

This article was externally peer-reviewed. An earlier version was originally published as the thesis for a master's degree in public health at the University of Washington.

Submitted 20 September 2005; revised 7 February 2006; accepted 10 February 2006.

From Tripler Army Medical Center, Honolulu, HI (RCO); and University of Washington School of Public Health and Community Medicine, Seattle, WA (SAAB, WEL).

Support: Funded by a grant from the Uniformed Services Academy of Family Physicians.

Conflict of interests: none reported.

Disclaimer: The views expressed in the article are those of the authors and do not reflect the official policy of the Department of the Army, the Department of Defense, or the U.S. Government.

Corresponding author: Robert C. Oh, MD, MPH, 3054 Ala Poha Place \#2101, Honolulu, HI 96818 (E-mail: roboh98@gmail.com). fruit and vegetable and lower sodium diets have been shown to reduce blood pressure. ${ }^{4,5}$ Despite evidence for benefits in CVD risk reduction, these diets have not yet shown all-cause mortality benefits. Recently, adoption of a Mediterranean diet has shown to reduce CVD and all-cause mortality in both primary and secondary prevention. ${ }^{6,7}$ The Mediterranean diet combines intake of moderate alcohol, fruits and vegetables, low to moderate amounts of fish and poultry, little red meat, and the use of olive oil as an important source of monounsaturated fats. ${ }^{8}$

One specific dietary recommendation in the battle against CVD may be the increased intake of $\omega 3$ fatty acids. ${ }^{9}$ Fatty fish such as salmon, mackerel, and herring are the primary sources of dietary $\omega 3$ fatty acids. The role of $\omega 3$ fatty acids and, more specifically, fish oil through diet or supplementation, in secondary prevention of CVD seems to be supported by cohort studies, ${ }^{10,11}$ randomized clinical trials, ${ }^{12-14}$ meta-analysis, ${ }^{15}$ and systematic review. ${ }^{16}$ Despite a recent review finding inconclusive results, ${ }^{17}$ the majority of the evidence seems to support the use of fish oils in secondary prevention of CVD. 
Several theories may explain fish oil's apparent benefit in CVD. Potential mechanisms have focused on fish oil's anti-inflammatory, ${ }^{18}$ anti-thrombotic, ${ }^{19}$ and potent triglyceride-lowering effect. ${ }^{20}$ Other studies have focused on antiarrhythmic ${ }^{21,22}$ properties of $\omega 3$ fatty acids in the reduction of sudden cardiac death. A large Italian study showed that $1 \mathrm{~g}$ of fish oil via diet or through supplementation decreased all-cause mortality by $16 \%-$ nearly all the benefit coming from reductions in sudden death. ${ }^{23}$ Due to the mounting evidence of the beneficial effects of $\omega 3$ fatty acids, the American Heart Association (AHA) updated its scientific statement in 2002. ${ }^{24}$ For patients with documented coronary artery disease, the AHA recommends $1 \mathrm{~g}$ of fish oil for all patients via diet or supplementation. It is unclear if physicians are making these recommendations to patients who would most benefit because no studies to date have looked at the frequency of general or fish-specific nutrition counseling by physicians for patients with known CVD. This study aims to determine the practices and associations of dietary fish prescribing among family physicians and to investigate their knowledge of fish oil supplementation and attitudes toward dietary practices.

\section{Methods}

\section{Study Population}

This cross-sectional survey of Washington State family physicians (chosen for convenience) was conducted at the University of Washington and approved by its Institutional Review Board.

\section{Survey Instrument}

We constructed a 22-item questionnaire that asked about physician practices, knowledge, and attitudes of dietary fish supplementation for patients with known cardiovascular disease. Dietary and fish prescribing practices were described using interval categories ranging from almost always $(>80 \%$ of the time), often $(60 \%$ to $80 \%)$, sometimes ( $40 \%$ to $59 \%)$, not often (20\% to $39 \%)$ to almost never $(<20 \%)$. Several case scenarios further categorized physician-prescribing practices (see Table 1). Questions regarding physician's knowledge of diet and its effects on CVD were derived from the medical literature. ${ }^{4,16,20,23,25-28}$ Fish-specific questions assessed knowledge of fish oil's effects on triglycerides, secondary prevention of cardiovascu-

\section{Table 1. Patient Scenarios}

Q5. Your patient is a 65-year-old male who recently suffered from a myocardial infarction. He does not have diabetes and his LDL cholesterol is currently $79 \mathrm{mg} / \mathrm{dL}$ on medications. His blood pressure is well controlled on a beta-blocker. He asks you for a diet to reduce his chance of 'another heart attack.' He is not overweight. Which diet would you recommend?

YOU MAY CHOOSE MORE THAN ONE

$\square$ Lower carbohydrate, higher protein diet (eg, Atkins, South Beach)

$\square$ Low saturated fat, high fruit and vegetable diet

$\square$ Increased intake of fatty fish meals, at least twice a week

$\square$ Low sodium diet

$\square$ None

$\square$ Other

Q6a. Another patient asks your opinion about a low carbohydrate, high protein diet (eg, Atkins, South Beach). $\mathrm{He}$ is similar to the patient in Q5 except he is $30 \mathrm{lbs}$ overweight. How do you respond to this patient?

$\square$ Strongly recommend it

$\square$ Recommend it

$\square$ No opinion

$\square$ Advise against it

$\square$ Strongly advise against it

Q6b. This same patient asks for your advice regarding dietary fish or supplementation. How do you respond?

$\square$ Strongly recommend it

$\square$ Recommend it

No opinion

Advise against it

Strongly advise against it

lar disease and sudden death. Questions evaluating attitudes toward dietary prescribing were modified from previous questionnaires ${ }^{29,30}$ to target prescribing specifically for CVD. Responses ranged from "strongly disagree" to "strongly agree" on a 5 -point Likert scale. Finally, questions regarding the number of patients with cardiovascular disease seen per week, nutritional training and general demographics (age, gender, medical and residency training, type of practice, faculty status) were included.

We conducted focus groups among peer physicians for internal consistency and pilot tested the survey for readability among resident and staff physicians. Multiple revisions were conducted before survey deployment.

\section{Sample Size Determination}

From pilot survey responses, $15 \%$ of physicians were predicted to be "high fish prescribers." To estimate this proportion with $95 \% \mathrm{CI}$ and a margin 
of error of $\pm 5 \%$, power analysis revealed that a sample of 178 physicians would be needed. Assuming a $30 \%$ to $50 \%$ mail response rate, a final sample size of 500 was chosen. After purchasing a database of active members of the American Academy of Family Physicians, we randomly selected 500 physicians from 1923 active members practicing in Washington State using a random sequence generator.

\section{Data Collection}

In October 2004, we mailed questionnaires with a cover letter explaining the study to the 500 randomly selected Washington State family physicians. We matched returned surveys to a secured, coded tracking list and sent a second mailing to those identified as nonrespondents approximately 4 weeks after the first.

\section{Data Analysis}

Dietary prescribing frequency was collapsed into 3 categories: high-prescribers (>60\%); moderate prescribers ( $40 \%$ to $59 \%$ ); and low prescribers $(<40 \%)$. Physicians who self-reported as high prescribers of dietary fish advice (advice to eat more fish or more fish oil supplements) and additionally prescribed a fish diet to the hypothetical CVD patient in Q5 (see Table 1) were classified as high fish prescribers. Responses to dietary knowledge questions were dichotomized into correct (2 points) or incorrect (0 points) using a standardized evidence-based approach. ${ }^{31}$ Demographic questions with more than 2 categories were collapsed into a 2-category response if any cell counts were less than 5 .

Descriptive statistics were used for physician dietary practices, attitudes, knowledge and demographics. Bivariate analyses of high fish prescribers with ordinal or interval variables were analyzed using the Mann-Whitney $U$ (MWU) test and categorical variables were analyzed using $\chi^{2}$ test and Fisher's exact test for those with cell counts $<5$. For multivariate analysis, models were employed using logistic regression to test for independent variables associated with high fish prescribers. From a full model including age, gender, all knowledge questions, all nutrition variables, and all attitude questions, reduced models were obtained and tested against larger models using likelihood ratio tests. Each of nutrition, attitude, and knowledge were tested as a separate group to assess their con- tribution to variation in high fish prescribing. The contribution of knowledge questions other than those relating to sudden death and of attitude questions other than those relating to perceived time available to counsel patients about nutrition (sufficient time) were also assessed using likelihood ratio tests. All data were analyzed using SPSS 11.0. All values were 2 -tailed, with values of $P<.05$ considered statistically significant.

\section{Results}

Of 500 mailed surveys, 260 were returned, for a response rate of $52.0 \%$. Respondents who did not see patients in a primary care setting $(n=20)$, did not see patients with CVD $(\mathrm{n}=2)$, declined to complete the survey $(\mathrm{n}=5)$, and surveys with missing key variables $(n=10)$ were excluded from final analysis. The response rate is less than ideal for generalizability of findings but is similar to other physician survey response rates. ${ }^{32}$ Nonetheless, no differences in age, gender, practice patterns, or other demographics were found between respondents with a full dataset and those with missing variables.

\section{Univariate Analysis}

\section{Demographics and Prescribing Practices}

Most physicians were male (59\%), 40 to 50 years of age, practiced in a non-academic office-setting and received training in the United States. Nearly all physician respondents (89\%) were moderate to high prescribers of general dietary advice to patients with known CVD. In contrast, most physicians were low prescribers of fish advice (see Table 2). Only $17 \%$ were identified as high fish prescribers-those who reported prescribing fish to their CVD patients greater than $60 \%$ of the time and who prescribed fish to the hypothetical CVD patient in Q5 (see Table 1).

When asked which dietary therapies they would offer the hypothetical patient with CVD in Q5 (see Table 1), 57\% recommended increasing fatty fish meals. Conversely, in the hypothetical scenario (Q6b) in which a similar patient specifically requests advice on dietary fish consumption, $93 \%$ of physicians would recommend or strongly recommend it.

\section{Dietary Knowledge and Attitudes}

Physicians scored higher answering general diet questions compared with fish questions (see Table 
Table 2. Background and Prescribing Practices of Washington State Family Physicians $(n=233)$

\begin{tabular}{lc}
\hline & $\%(\mathrm{n})$ \\
\hline Age & \\
$\quad<40$ years old & $39.9(89)$ \\
41 to 50 years old & $30.5(68)$ \\
$>50$ years old & $29.6(66)$ \\
Gender & \\
Male & $132(59.2)$ \\
Female & $91(40.8)$ \\
CVD* patients seen per week & \\
1 to 10 & $52.5(117)$ \\
11 to 20 & $30.5(68)$ \\
21 to 30 & $13.0(29)$ \\
$>30$ & $4.0(9)$ \\
Nutrition training (any) & $90.6(202)$ \\
CME & $74.4(166)$ \\
Medical school & $51.6(115)$ \\
Residency & $53.4(119)$ \\
Other & $22.9(51)$ \\
Prescriber of dietary advice† & \\
Low (<40\%) & \\
Moderate $(40 \%$ to $60 \%)$ & $10.7(24)$ \\
High $(>60 \%)$ & $20.2(45)$ \\
Prescriber of fish advice† & $69.0(154)$ \\
Moderate $(40 \%$ to $60 \%)$ & \\
High $(>60 \%)$ & $53.3(119)$ \\
& $21.5(48)$ \\
& $25.1(56)$ \\
\hline
\end{tabular}

* CVD, cardiovascular disease; CME, continuing medical education.

$\dagger$ Represents frequency of advice given by respondents to patients with known CVD and categorized into low, moderate, and high prescribers.

3). Attitudes toward dietary advice in CVD are presented in Table 3.

\section{Bivariate Analysis}

No significant associations were found between high fish prescribers and demographics, practice environment or nutrition training variables. Physicians who knew that fish oil was beneficial in sudden death reduction were significantly more likely to be high fish prescribers ( $\chi^{2}$ test; $\left.P=.005\right)$. In addition, physicians who were high fish prescribers were significantly more likely to report that they had more time available to adequately advise their patients about nutrition (MWU; $P=.02$ ). Other associations with high fish prescribers and dietary knowledge and attitudes are presented in Table 4.
Table 3. Dietary Knowledge and Attitudes of Washington State Family Physicians $(n=223)$

\begin{tabular}{lc}
\hline Dietary Knowledge* & $\begin{array}{c}\text { Percent } \\
\text { Answering } \\
\text { Correctly (n) }\end{array}$ \\
\hline General diet questions & \\
Antioxidants do not reduce CVD $\dagger$ & $76.2(170)$ \\
Low sodium diets lower blood pressure & $70.4(157)$ \\
Fruits and vegetables lower blood pressure & $32.7(73)$ \\
Fish questions & \\
Fish oil reduces CVD & $56.5(126)$ \\
Fish oil reduces triglycerides & $43.0(96)$ \\
Fish oil reduces sudden cardiac death & $26.5(59)$ \\
Dietary attitudes & Agree (\%) \\
Nutrition has an important part to play in the & 99.1 \\
$\quad$ prevention of CVD & \\
The primary care physician has an essential & 91.9 \\
$\quad$ role in giving dietary advice & \\
Advice given will impact on what people eat & 66.8 \\
Advice given will be effective in reducing & 52.5 \\
$\quad$ CVD & \\
The primary care physician has sufficient time & 18.8 \\
to advise patients adequately & \\
\hline
\end{tabular}

* Statements represent correct answers to knowledge questions. † CVD, cardiovascular disease.

₹ Strongly agree or agree.

\section{Multivariate Analysis}

Statistical models were explored to determine independent factors associated with high fish prescribers. In the full model, demographic variables (age and gender) were included with all fish knowledge variables (knowledge of fish effects on CVD, sudden death, and triglycerides), dietary attitude variables (those that asked specifically about CVD and sufficient time), and nutrition training variables (continuing medical education, medical school, residency, and other). More parsimonious models were explored, removing factors in groups that did not contribute independent statistical information. In this way, the nutrition training variables were removed. The contribution of the additional attitude variables beyond sufficient time were not significant nor were knowledge variables beyond the one relating to sudden death.

Multiple logistic regression analysis revealed that knowledge of the effect of fish oil on sudden death was significantly associated with high fish prescribing behaviors in all models. The final model, independent of age, gender, and sufficient time, included an effect estimate of this knowledge variable of $2.77,95 \%$ CI 1.32 to 5.82 . Similarly, 


\begin{tabular}{|c|c|c|c|}
\hline & \multicolumn{2}{|c|}{ High Fish Prescribers } & \\
\hline & $\begin{array}{c}\text { No } \\
(\mathrm{n}=185)\end{array}$ & $\begin{array}{c}\text { Yes } \\
(\mathrm{n}=38)\end{array}$ & \\
\hline \multicolumn{4}{|l|}{ DIETARY KNOWLEDGE } \\
\hline General diet questions (correctly answered) & $\%(n)$ & $\%(n)$ & $P$ Value* \\
\hline Antioxidants do not reduce CVD $†$ & $77(143)$ & $71(27)$ & .410 \\
\hline Low sodium diets lower blood pressure & $71(131)$ & $68(26)$ & .769 \\
\hline Fruits and vegetables lower blood pressure & $32(59)$ & $37(14)$ & .554 \\
\hline \multicolumn{4}{|l|}{ Fish questions (correctly answered) } \\
\hline Fish oil reduces CVD & $54(100)$ & $68(26)$ & .104 \\
\hline Fish oil reduces triglycerides & $42(77)$ & $50(19)$ & .342 \\
\hline Fish oil reduces sudden cardiac death & $23(42)$ & $45(17)$ & .005 \\
\hline \multicolumn{4}{|l|}{ NUTRITION TRAINING } \\
\hline Any & $89(165)$ & $97.4(37)$ & $.138 \neq$ \\
\hline CME & $28(134)$ & $15.7(6)$ & .131 \\
\hline Medical school & $49.7(92)$ & $60.5(23)$ & .225 \\
\hline Residency & $52.4(97)$ & $57.9(22)$ & .539 \\
\hline Other & $23.8(44)$ & $18.4(7)$ & .473 \\
\hline DIETARY ATTITUDES & & & $P$ Value $\$$ \\
\hline \multicolumn{4}{|l|}{$\begin{array}{l}\text { Nutrition has an important part to play in the } \\
\text { prevention of CVD }\end{array}$} \\
\hline Neutral & $1.1(2)$ & - & .730 \\
\hline Agree & $32.4(60)$ & $36.8(14)$ & \\
\hline Strongly agree & $66.5(123)$ & $63.3(24)$ & \\
\hline \multicolumn{4}{|l|}{$\begin{array}{l}\text { The primary care physician has an essential role } \\
\text { in giving dietary advice }\end{array}$} \\
\hline Strongly disagree & $0.5(1)$ & - & .309 \\
\hline Disagree & $1.1(2)$ & - & \\
\hline Neutral & $7.0(13)$ & $5.3(2)$ & \\
\hline Agree & $44.3(82)$ & $39.5(15)$ & \\
\hline Strongly agree & $47.0(87)$ & $55.3(21)$ & \\
\hline \multicolumn{4}{|l|}{ Advice given will impact on what people eat } \\
\hline Disagree & $8.6(16)$ & $7.9(3)$ & .841 \\
\hline Neutral & $24.3(45)$ & $26.3(10)$ & \\
\hline Agree & $55.1(102)$ & $50.0(19)$ & \\
\hline Strongly agree & $11.9(22)$ & $15.8(6)$ & \\
\hline \multicolumn{4}{|l|}{ Advice given will be effective in reducing CVD } \\
\hline Strongly disagree & $0.5(1)$ & - & .095 \\
\hline Disagree & $7.6(14)$ & $5.3(2)$ & \\
\hline Neutral & $41.6(77)$ & $31.6(12)$ & \\
\hline Agree & $43.8(81)$ & $50.0(19)$ & \\
\hline Strongly agree & $6.5(12)$ & $13.2(5)$ & \\
\hline \multicolumn{4}{|l|}{$\begin{array}{l}\text { The primary care physician has sufficient time to } \\
\text { advise patients adequately }\end{array}$} \\
\hline Strongly disagree & $29.7(55)$ & $15.8(6)$ & .018 \\
\hline Disagree & $41.6(77)$ & $36.8(14)$ & \\
\hline Neutral & $11.9(22)$ & $18.4(7)$ & \\
\hline Agree & $15.7(29)$ & $28.9(11)$ & \\
\hline Strongly agree & $1.1(2)$ & & \\
\hline
\end{tabular}

* CVD, cardiovascular disease; CME, continuing medical education.

$\dagger \chi^{2}$ test.

$\ddagger$ Fisher's exact test.

$\$$ Mann-Whitney $U$. 
perception that there was sufficient time available to counsel patients, was associated with high fish prescribing, independent of age, gender, and knowledge of sudden death, OR $=1.43,95 \% \mathrm{CI}$ 1.03 to 1.98 .

\section{Discussion}

Increased intake of $\omega 3$ fatty acids in the form of fish oil (through diet or supplementation) may reduce mortality in patients with CVD. ${ }^{2,33}$ This study reveals that despite favorable attitudes toward diet and knowledge of fish oil's cardiovascular benefits, Washington State family physicians do not often recommend this potentially life-saving intervention to their patients with CVD. In addition, our study is the first to attempt to determine associations of fish prescribing. Knowledge of fish oil's benefit in sudden death reduction and the perceived time available to counsel patients were independently associated with higher fish prescribing.

Previous studies looking at dietary advice in the general population have highlighted the gaps between highly favorable attitudes toward nutrition and physicians' health promotion behavior and performance. $^{29,30}$ Similarly, in this study, nearly all respondents felt strongly about providing nutritional advice to patients with CVD and felt that primary care physicians play important roles in providing dietary advice. Consistent with these values, the vast majority of family physicians (89\%) reported that they offer some type of dietary advice to their patients with cardiovascular disease. However, this positive attitude did not translate into reported higher fish prescribing. When asked specifically about fish advice, only $17 \%$ of family physicians were identified as high fish prescribers.

Findings from this study show that research studies into methods that increase fish oil prescribing to CVD patients is necessary because physicians' prescribing behaviors are complex. ${ }^{34}$ For example, despite expert recommendations backed by evidence-based research, physicians often do not follow clinical practice guidelines. ${ }^{35,36}$ To promote changes in physician behavior, potential interventions should be examined not only at the physician level, but also in the context of the illness, patient, and working environment. ${ }^{37}$ Lack of knowledge and training were potential barriers for primary care physicians in other studies looking at general nutritional counseling. ${ }^{38-40}$ In this study, the ma- jority of physicians correctly answered that fish oil was effective in secondary prevention of CVD, but this knowledge was not independently associated with higher fish prescribing. Similarly, we found no significant association between knowledge and fish oil prescribing for those who correctly knew of fish oil's effect on hypertriglyceridemia. Physicians' knowledge of fish oil's effects on sudden death remained significant in multivariate analysis when controlling for other variables. Thus, knowledge of fish oil's effect on sudden death seems to be independently associated with higher fish prescribing behavior. The largest randomized trial suggested that most of the mortality benefits of fish oil was from sudden death reduction. ${ }^{14,23}$ We theorize that specific knowledge of sudden death reduction may be both important and persuasive enough to improve recommendations over a general knowledge of fish benefits in CVD. Contrary to other studies which revealed a lack of nutrition training as a barrier to dietary prescribing, ${ }^{39,41}$ we did not show any relationship with high fish prescribers and general nutrition training. Our survey, however, did not query physicians regarding specific training on fish nutritional advice. Despite other knowledge deficits regarding the benefits of fish oil, this study suggests the need for future investigations on enhancing physician education of fish oil-focusing specifically on its life-saving properties.

Our study also reveals the effects of the perception of "sufficient time" on prescribing behavior. The physicians who perceived more time available to counsel their patients were significantly associated with higher fish prescribing. This was found in the full model and also the parsimonious model. Because of the myriad of recommendations and guidelines expected to be performed in today's 15minute office visit, most physicians may not have time to give complex nutritional guidance to their patients. Chronic disease models of health care and multidisciplinary approaches with certified nutritionists may be an improved approach for patients with CVD. Physician counseling and recommendations should not be undervalued. Instead, physicians need concise recommendations for their patients to be most effective with limited time. Brief, low-intensity nutritional counseling, in combination with a self-help manual, has shown to be effective in promoting dietary change. ${ }^{42}$ Communication based on AHA recommendations ${ }^{24}$ is easy to understand and can be quick to implement. For 
patients with CVD, the AHA recommends $1 \mathrm{~g}$ per week of fish oil via diet (approximately 2 fatty fish meals) or supplementation.

Patient-initiated requests can influence physician prescribing. ${ }^{43}$ In this study, when a hypothetical patient requested advice regarding fish, physicians' recommendation rates jumped from $57 \%$ to $93 \%$. Intuitively, low-risk interventions that are backed by evidence and currently under-utilized are more likely to be recommended when patients initiate a request. ${ }^{44}$ This may be related to the perceived time barriers as described previously. $\mathrm{Pa}-$ tient-initiated requests may improve rates of fish prescribing by physicians and reduce the time and efforts associated with its recommendation.

Finally, with the confusion about mercury and other environmental contaminants in dietary fish, supplementation may be a more consistent and safer way to provide fish oil. ${ }^{45,46}$ Over-the-counter fish oil capsules, which typically contain $300 \mathrm{mg}$ of fish oil, can be taken 3 times a day to provide adequate protection for secondary prevention. ${ }^{47} \mathrm{~A}$ recently approved prescription of a purified and concentrated form of $\omega 3$-acid ethyl esters ${ }^{48}$ provides $900 \mathrm{mg}$ of $\omega 3$ fatty acids and may improve compliance and reliability.

Findings from our study should be interpreted with caution. We acknowledge that the reported prescribing practices of Washington State family physicians may not generalize to all primary care physicians. However, the profile of the physicians surveyed was similar to a recent survey, ${ }^{49}$ and is probably generalizable to Washington State family physicians. Washington State is known for its abundance of salmon and physicians practicing in that State could potentially be biased by their practice environment. However, this would probably bias favorably toward fish prescribing, and the actual proportion of high fish prescribers nationwide may be lower than observed in this study. Selection and reporting bias also limits most survey research and self-reports of nutrition advice may not always accurately measure true behavior. Other studies looking at frequency of dietary advice given to the general population by physicians reported overall lower recommendation rates, ${ }^{30,50}$ but these surveys did not look at dietary advice given specifically to patients with CVD. Reports suggests that physicians provide diet and exercise advice at higher rates to those at highest risk for cardiovascular events, ${ }^{51,52}$ and thus physicians should prescribe dietary advice to their patients with CVD more frequently than they do to the general population.

\section{Conclusion}

Fish oil intake, through diet or supplementation, is recommended by the AHA and can potentially reduce mortality in patients with CVD. Despite this, family physicians do not often advise increasing dietary fish intake to their patients with CVD. Improving physician awareness of fish oil's benefits on sudden death and simplifying the message should be explored further as potential strategies to increase physician recommendation of this important advice.

Contributorship: Dr. Oh takes responsibility for the overall study and data integrity. Study concept and design, Oh, Beresford, and Lafferty; drafting of manuscript, $\mathrm{Oh}$; critical revision of the manuscript for important intellectual content, Oh, Beresford, and Lafferty; and statistical analysis, Oh and Beresford.

\section{References}

1. Mortality Data from the National Vital Statistics System. Accessed on May 12, 2005 at: http://www. cdc.gov/nchs/about/major/dvs/mortdata.htm.

2. Kromhout D, Menotti A, Kesteloot H, Sans S. Prevention of coronary heart disease by diet and lifestyle. Evidence from prospective cross-cultural, cohort and intervention studies. Circulation 2002;105: 893-8.

3. National Cholesterol Education Program (NCEP) expert panel on detection, evaluation, and treatment of high blood cholesterol in adults (Adult Treatment Panel III). Third report of the National Cholesterol Education Program (NCEP) expert panel on detection, evaluation, and treatment of high blood cholesterol in adults (Adult Treatment Panel III) final report. Circulation 2002;106:3143-421.

4. Appel LJ, Moore TJ, Obarzanek E, et al, for the DASH Collaborative Research Group. A clinical trial of the effects of dietary patterns on blood pressure. N Engl J Med 1997;336:1117-24.

5. Sacks FM, Svetley LP, Vollmer WM, et al. Effects on blood pressure of reduced dietary sodium and the dietary approaches to stop hypertension (DASH) diet. DASH-Sodium Collaborative Research Group. N Engl J Med 2001;334:3-10.

6. Trichopoulou A, Costacou T, Bamia C, Trichopoulos D. Adherence to a Mediterranean diet and survival in a Greek population. N Engl J Med 2003;348: 2599-608.

7. de Lorgeril M, Salen P, Martin JL, et al. Mediterranean diet, traditional risk factors, and the rate of cardiovascular complications after myocardial infarc- 
tion: final report of the Lyon Diet Heart Study. Circulation 1999;99:779-85.

8. American Heart Association. What is the "Mediterranean" diet? Accessed December 11, 2005 at: http:// www.americanheart.org/presenter.jhtml? identifier $=$ 4644.

9. Yancy WS, Westman EC, French PA, Califf RM. Diets and clinical coronary events: the truth is out there. Circulation 2003;107:10-6.

10. Kromhout D, Bosschieter EB, de Lezenne CC. The inverse relation between fish consumption and 20year mortality from coronary heart disease. $\mathrm{N}$ Engl J Med 1985;312:1205-9.

11. Daviglus ML, Stamler J, Orencia AJ, et al. Fish consumption and the 30-year risk of fatal myocardial infarction. N Engl J Med 1997;336:1046-53.

12. Singh RB, Niaz MA, Sharma JP, Kumar R, Rastogi V, Moshiri M. Randomized, double-blind, placebocontrolled trial of fish oil and mustard oil in patients with suspected acute myocardial infarction: the Indian experiment of infarct survival-4. Cardiovasc Drugs Ther 1997;11:485-91.

13. Burr ML, Fehily AM, Gilbert JF, et al. Effects of changes in fat, fish and fibre intakes on death and myocardial reinfarction: diet and reinfarction trial (DART). Lancet 1989;2:757-61.

14. GISSI-Prevenzione Investigators. Dietary supplementation with n-3 polyunsaturated fatty acids and vitamin $\mathrm{E}$ after myocardial infarction: results of the GISSI-Prevenzione trial. Lancet 1999;354:447-55.

15. Bucher HC, Hengstler P, Schindler C, et al. N-3 polyunsaturated fatty acids in coronary heart disease: a meta-analysis of randomized controlled trials. Am J Med 2002;112:298-304.

16. Wang C, Chung M, Lichtenstein A, et al. Effects of $\omega 3$ fatty acids on cardiovascular disease. Evidence report/technology assessment no. 94 (prepared by Tufts-New England Medical Center Evidencebased Practice Center, under contract no. 290-020022). AHRQ Publication No. 04-E009-2. Rockville (MD): Agency for Healthcare Research and Quality. March 2004.

17. Hooper L, Thompson RL, Harrison RA, et al. Omega-3 fatty acids for prevention and treatment of cardiovascular disease. Cochrane Database Syst Rev 2004;(4):CD003177.

18. Endres S, Ghorbani R, Kelly VE, et al. The effect of dietary supplementation with n-3 fatty acids on the synthesis of interleukin-1 and tumor necrosis factor by mononuclear cells. N Engl J Med 1989;320:26570 .

19. Holub BJ. Clinical nutrition: 4. omega-3 fatty acids in cardiovascular care. CMAJ 2002;166:608-15.

20. Balk E, Chung M, Lichtenstein A, et al. Effects of omega-3 fatty acids on cardiovascular risk factors and intermediate markers of cardiovascular disease. Evidence report/technology assessment no. 93 (prepared by Tufts-New England Medical Center Evi- dence-based Practice Center under contract no. 29002-0022). AHRQ Publication No. 04-E010-2. Rockville (MD): Agency for Healthcare Research and Quality. March 2004.

21. Leaf A, Kang JX, Xiao YF, Billman GE. Clinical prevention of sudden cardiac death by n-3 polyunsaturated fatty acids and mechanism of prevention of arrhythmias by n-3 fish oils. Circulation 2003;107: 2646-52.

22. Dallongeville J, Yamell J, Ducimetiére P, et al. Fish consumption is associated with lower heart rates. Circulation 2003;108:820-5.

23. Marchioli R, Barzi F, Bomba E, et al. Early protection against sudden death by n-3 polyunsaturated fatty acids after myocardial infarction: time course analysis of the results of the Gruppo Italiano per lo Studio della Sopravvivenza nell'Infarto Miocardico (GISSI)-Prevenzione. Circulation 2002;105:1897-903.

24. Kris-Etherton PM, Harris WS, Appel LJ. AHA scientific statement: fish consumption, fish oil, omega-3 fatty acids, and cardiovascular disease. Circulation 2002;106:2747-57.

25. Vivekananthan DP, Penn MS, Sapp SK, Hsu A, Topol EJ. Use of antioxidant vitamins for the prevention of cardiovascular disease: meta-analysis of randomised trials. Lancet 2003;361:2017-23.

26. He FJ, MacGregor GA. Effect of longer-term modest salt reduction on blood pressure. The Cochrane Database of Systematic Reviews 2004, issue 1. art. no.: CD004937. DOI: 10.1002/14651858.

27. Kris-Etherton PM, Lichtenstien AH, Howard BV, Steinberg D, Witztum JL. Antioxidant vitamin supplementation and cardiovascular disease. Circulation 2004;110:637-41.

28. Albert CM, Campos H, Stampfer MJ, et al. Blood levels of long-chain n-3 fatty acids and the risk of sudden death. N Engl J Med 2002;346:1113-8.

29. Moore H, Adamson AJ. Nutrition interventions by primary care staff: a survey of involvement, knowledge and attitude. Public Health Nutr 2002;5:531-6.

30. Levine BS, Wigren MM, Chapman DS, Kerner JF, Bergman RL, Rivlin RS. A national survey of attitudes and practices of primary-care physicians relating to nutrition: strategies for enhancing the use of clinical nutrition in medical practice. Am J Clin Nutr 1993;57:115-9.

31. Ebell MH, Siwek J, Weiss BD, et al. Strength of recommendation taxonomy (SORT): a patient-centered approach to grading evidence in the medical literature. Am Fam Physician 2004;69:548-56.

32. Asch DA, Jedrziewski MK, Christakis NA. Response rates to mail surveys published in medical journals. J Clin Epidemiol 1997;50:1129-36.

33. Studer M, Brier M, Leimenstoll B, Glass TR, Bucher HC. Effect of different antilipidemic agents and diets on mortality. Arch Intern Med 2005;165: $725-30$ 
34. Naylor CD. The complex world of prescribing behavior. JAMA 2004;291:104-6.

35. Cabana MD, Rand CS, Powe NR, et al. Why don't physicians follow clinical practice guidelines? A framework for improvement. JAMA 1999;282:145865.

36. McGlynn EA, Asch SM, Adams J, et al. The quality of health care delivered to adults in the United States. N Engl J Med 2003;348:2635-45.

37. Grol R, Wensing M. What drives change? Barriers to and incentives for achieving evidence-based practice. Med J Aust 2004;180(Suppl):S57-60.

38. Mihalynuk TV, Scott SC, Coombs JB. Self-reported nutrition proficiency is positively correlated with the perceived quality of nutrition training of family physicians in Washington State. Am J Clin Nutr 2003; 77:1330-6.

39. Hiddink GJ, Hautvast J, van Woerkum CV, van't Hof MA, Fieren CJ. Cross-sectional and longitudinal analyses of nutrition guidance by primary care physicians. Eur J Clin Nutr 1999;53 Suppl:S35-43.

40. Kushner RF. Barriers to providing nutrition counseling by physicians: a survey of primary care practitioners. Prev Med 1995;24:546-52.

41. Hiddink GJ, Hautvast JG, van Woerkum CM, Fieren CJ, van't Hof MA. Nutrition guidance by primary-care physicians: perceived barriers and low involvement. Eur J Clin Nutr 1995;49:842-51.

42. Beresford SA, Curry SJ, Kristal AR, Lazovich D, Feng Z, Wagner EH. A dietary intervention in primary care practice: the eating patterns study. Am J Public Health 1997;87:610-6.

43. Kravitz RL, Epstein RM, Feldman MD, et al. Influence of patients' requests for direct-to-consumer advertised antidepressants. JAMA 2005;293:1995-2002.

44. Hollon MF. Direct-to-consumer advertising. A hap- hazard approach to health promotion. JAMA 2005; 293:2030-3.

45. Foran SE, Flood JG, Lewandrowski KB. Measurement of mercury levels in concentrated over-thecounter fish oil preparations. Arch Pathol Lab Med 2003;127:1603-5.

46. Melanson SF, Lewandrowski EL, Flood JG, Lewandrowski KB. Measurement of organochlorines in commercial over-the-counter fish oil preparations: implications for dietary and therapeutic recommendations for omega-3 fatty acids and a review of the literature. Arch Pathol Lab Med 2005;129:74-7.

47. Oh R. Practical applications of fish oil (omega-3 fatty acids) in primary care. J Am Board Fam Pract 2005; $18: 28-36$.

48. US Food and Drug Administration. Consumer drug information sheet: Omacor. Accessed November 21, 2005 at: http://www.fda.gov/cder/consumerinfo/ druginfo/omacor.htm

49. Seehusen DA, Baldwin LM, Runkle GP, Clark GC. Are family physicians appropriately screening for postpartum depression? J Am Board Fam Pract 2005; 18:104-12.

50. Weshsler H, Levine S, Idelson RK. The physician's role in health promotion revisited-a survey of primary care practitioners. N Engl J Med 1996;334: 996-8.

51. Greenlund KJ, Giles WH, Keenan NL, Croft JB, Mensah GA. Physician advice, patient actions, and health-related quality of life in secondary prevention of stroke through diet and exercise. Stroke 2002;33: 565-70.

52. Physician advice and individual behaviors about cardiovascular disease risk reduction-seven states and Puerto Rico, 1997. MMWR Morb Mortal Wkly Rep $1999 ; 48: 74-7$. 